\title{
Ethics of Resource Allocation and Rationing Medical Care in a Time of Fiscal Restraint - US and Europe
}

\author{
Steven Teutsch, MD, MPH, ${ }^{1}$ \\ Bernd Rechel, MA, $\mathrm{PhD}^{2}$
}

\begin{abstract}
Background: All resources are scarce. The ethical dilemma in health care is how to balance the precepts of autonomy, beneficence, and distributive justice. Rationing may affect three dimensions of coverage: the share of the population covered, the services covered, and the extent to which services are covered.
\end{abstract}

United States: The US spends 50 percent more per capita on health care than any other country while achieving worse health than many. Poorly coordinated insurance mechanisms leave 19 percent of the population uninsured. Until passage of the Patient Protection and Affordable Care Act (PPACA) in 2010, health care was effectively a privilege, not a right. While PPACA seeks to rectify this, by 2019 five percent of non-elderly US residents will likely remain uninsured.

Europe: Most European countries provide universal or near-universal population coverage to people resident in the respective country. Central and Eastern European countries inherited the Soviet-era commitment to universal coverage free at the point of use. Faced with a decline in government spending on health, almost all of them reduced the scope of services and introduced official user fees. In contrast, other European countries expanded entitlement to publicly funded health care, resulting in greater equity. A number of countries have attempted to depoliticize decisions on rationing by using health technology assessments and dedicated agencies.

Discussion: Resource allocation and rationing differ considerably between the US and Europe. In the US, where social welfare remains controversial, there are few restrictions on the use of health care technology regardless of cost or clinical effectiveness. European countries engage in more explicit debates about these limits, though these are complicated by media and lobby power.

\footnotetext{
${ }^{1}$ Chief Science Officer, Los Angeles County Department of Public Health

${ }^{2}$ Researcher, European Observatory on Health Systems and Policies, and Honorary Senior Lecturer, London School of Hygiene \& Tropical Medicine
}

Corresponding Author Contact Information: Steven Teutsch at steutsch@ph.lacounty.gov; Los Angeles County Dept of Public Health, 313 N Figueroa St, Rm 708, Los Angeles, CA 90012, USA 
Conclusion: The ethical issues in the US largely revolve around rationing care by eligibility for insurance coverage, whereas in Europe they are more concerned with the scope of publicly funded services to all. On both sides of the Atlantic, public debates are needed about the financial sustainability of health systems, the tradeoffs between cost-containment and broader societal and health system goals, the role of the welfare state, and the limits of publicly financed health care.

Keywords: Public health, ethics, resource allocation, rationing, health care policy, United States, Europe

Recommended Citation: Teutsch S, Rechel B. Ethics of resource allocation and rationing medical care in a time of fiscal restraint - US and Europe. Public Health Reviews. 2102;34: epub ahead of print.

\section{INTRODUCTION}

At some level, all resources are scarce and that is certainly true for health care. In the face of scarcity, resources are either explicitly or implicitly rationed. Rationing of health care limits access to beneficial health care services. ${ }^{1}$ The central question, then, is not whether health care is rationed, but how, by whom and to what degree. The ethical dilemma is how to balance the precepts of autonomy, beneficence, and distributive justice. ${ }^{2}$ Autonomy would suggest that individuals have a right to determine what is in their own best interest, though that interest may be limited if exercising that right limits the rights of others. Beneficence means that clinicians should act completely in the interest of their patients, and distributive justice or equity implies fairness and that all groups have an equal right to clinical services regardless of race, gender, age, income, or any other characteristic. The utilitarian perspective would suggest that resources for medical care should be used to provide the greatest good for the greatest number. However, in medical care, the "rule of rescue" is often invoked to provide services to the neediest or the most identifiable. A corollary is that therapeutic services are often given primacy over preventive services regardless of their cost effectiveness. Different countries balance the rights of individuals and the fairness in society as a whole in very different ways and use very different processes for addressing the legitimacy, transparency, and accountability of those explicit or implicit decisions.

Ultimately, rationing has to be assessed against these broader societal and health system goals. Health system goals can be defined in a number of ways. One of the most widely quoted attempts, the WHO World Health Report 2000, defined the fundamental objectives of health systems as improving population health, responding to people's expectations, and 
providing financial protection against the costs of ill health. ${ }^{3}$ Health, of course, is not only determined by health care, but also by broader social and environmental factors. While equity in health care financing and in access to health care services can reduce inequities, equity in health outcomes should be another goal of health systems. ${ }^{4,5}$

\section{TYPES OF RATIONING}

All health care systems rely on a mix of public and private systems of financing and decisions on rationing are made by actors in both the public and private sector, with important differences between the United States and Europe. Overall, rationing can affect three dimensions of coverage: breadth (the share of the population covered), scope (which services are covered) and depth (the extent or cost share to which services are covered). ${ }^{5}$

Implicitly or explicitly rationing the breadth of coverage reduces the proportion of the population eligible for coverage. This can be through means-testing (e.g., excluding those with higher incomes), employment (e.g., excluding self-employed people), pricing them out of the market (e.g., by making coverage unaffordable for people with pre-existing conditions), excluding people from eligibility (e.g., those who do not meet certain residency requirements), or by allowing people to opt out.

Rationing the scope of care by excluding services from the benefits package (which may be implicit or explicit and based on a positive or negative list) reduces the quantity or quality of clinical care. This can be achieved through application of criteria and measures such as effectiveness, comparative effectiveness, or cost-effectiveness, and making use of such tools as health technology assessments (HTAs), clinical guidelines or quality assurance. ${ }^{6}$ Many health care systems also ration the scope of care by waiting lists.

Rationing the depth of coverage involves user charges. These can be based on the value of health care services and imply selective charges (co-payments) for inefficient services or reduced charges for especially valuable ones (value-based insurance design). ${ }^{7}$ It can also apply only to certain groups of patients, based on eligibility criteria or defined health needs. More generalized user charges shift costs to private households and may undermine access of lower income groups of the population. ${ }^{8}$ This illustrates that all forms of rationing involve ethical issues and decisions on how to balance fiscal constraints with health care system goals such as equity, efficiency and improving population health, as well as broader societal values. ${ }^{9,10}$ 
Rationing the different dimensions of coverage takes place at all levels, often in an implicit rather than explicit manner. ${ }^{11}$ In line with the wider health system goals of transparency, accountability and patient responsiveness, the process of setting priorities and rationing coverage (particularly of publicly funded care) should be based on explicit criteria and a broad public debate involving government, providers, the public, and patients. ${ }^{9}{ }^{12}$ However, this does not regularly happen in practice and it is often easier for governments (or, in the US, employers) to instead exclude whole areas of services, such as dental care. ${ }^{8}$ Furthermore, much "bedside" rationing by clinicians, such as on the basis of age, ${ }^{13}$ has been traditionally implicit and unsystematic. ${ }^{11,12}$

\section{RESOURCE ALLOCATION AND RATIONING IN THE US}

The US spends 50 percent more per capita on health care than any other country in the world, some 17.6 percent of GDP in $2009,{ }^{14}$ while achieving poorer health than many OECD countries. ${ }^{15}$ At a macro level, medical care consumes approximately 97 percent of the health budget—only three percent is devoted to public health - with concomitant neglect of many social and environmental determinants of health. ${ }^{16}$ In medical care, poorly coordinated insurance mechanisms foster a system that leaves 19 percent of the US population uninsured and over USD $\$ 750$ billion wasted annually in unnecessary services (USD $\$ 210$ billion), administrative waste (USD $\$ 190$ billion), inefficiently delivered services (USD $\$ 130$ billion), high prices (USD \$105 billion), fraud (USD $\$ 75$ billion), and missed prevention opportunities (USD \$55 billion). ${ }^{17,18}$

Passage of the Patient Protection and Affordable Care Act (PPACA) in 2010 was meant to change health care from a privilege to a right. Previously, insurance coverage was available to those who could afford to purchase individual insurance and members of certain groups (largely families of workers whose employers paid for coverage), while the elderly (age 65 and older) and disabled were covered through the federal Medicare program and the poor were entitled to the Medicaid program, but with varying entitlements across states. Many fell between the cracks in the system. In particular those with pre-existing conditions are still often denied individual coverage or charged exorbitant rates, while young adults and undocumented or newly arrived residents had little recourse other than to pay cash for care or rely on emergency room or charity care. Thus, in part, health care resources were allocated based on who was covered by insurance schemes, disenfranchising many who could not afford insurance. 
Because of the perceived sanctity of the physician - patient relationship and individual decision-making, resources are not limited to services that provide value, but, rather, are up to the choices of physicians and patients. Physicians and institutions often profit directly from delivery of services through fees and ownership of facilities and equipment, resulting in strong incentives for overuse. Lack of an integrated system of electronic health records leads to needlessly repeated testing, while the lack of critical clinical information gives rise to poor decisions and untoward consequences, such as unnecessary drug interactions. The threat of malpractice abets overuse of clinical care. Incentives are thus poorly aligned with need and appropriate use. Heavy promotion of costly drugs and procedures along with a lack of price sensitivity on the part of physicians and patients further contributes to overuse, though tiered drug co-payments are used to encourage use of less costly drugs.

While PPACA seeks to rectify some of these problems, such as beginning to standardize a minimum level of coverage, providing full coverage of clinical preventive services, and assuring that health care coverage is available to most without regard to pre-existing conditions, current estimates are that by 2019, five percent of non-elderly US residents will remain uninsured despite the new incentives for coverage and negative tax consequences of remaining uninsured. PPACA also established the Patient-Centered Outcomes Research Institute (PCORI) to oversee the conduct of comparative effectiveness studies. These should inform coverage decisions, though Medicare is expressly forbidden from using economic evaluations in those coverage decisions. It is too early to assess PCORI's impact on coverage and access to medical services.

\section{RESOURCE ALLOCATION AND RATIONING IN EUROPE}

In most European countries, the dominant source of health financing is public, based on taxation and social insurance contributions. Although in several poorer former Soviet countries, in particular in the Caucasus and Central Asia, private out-of-pocket expenditure has become the main source of health financing. ${ }^{19,20}$ Curative or rehabilitative services usually comprise the largest share of total health expenditure. Expenditure on prevention and public health services as a percentage of total health expenditure varies substantially across countries, ranging in 2009 in the European Economic Area (EEA) from 1.2 percent in Lithuania to 8.3 percent in Romania. ${ }^{21}$ 
Most health care systems in Europe (as well as Australia, Canada and Japan), whether they are predominantly tax- or insurance-financed, provide universal or near-universal population coverage to all people resident in the respective country. Health benefits are comprehensive and usually include preventive and public health services, primary care, ambulatory and inpatient care, prescription pharmaceuticals, mental health care, dental care, rehabilitation, home care and nursing home care. ${ }^{19}$

The countries of Central and Eastern Europe formerly belonging to the Soviet bloc faced a different situation: they had inherited the Soviet-era commitment to universal coverage for a comprehensive range of services free at the point of use. However, this commitment used to be poorly financed in the Soviet period and was increasingly difficult to meet, as many countries faced severe transitional recessions in the 1990s, with a corresponding drop in government expenditure on health and a rise in informal out-of-pocket payments. Almost all former communist countries responded by defining benefit packages with a reduced scope of services and introducing official user fees for services outside the benefit packages, although in several countries, ranging from Hungary to Tajikistan, this met with considerable - and often-successful resistance. ${ }^{20,22,23}$ Despite differences in coverage, the role of both formal and informal out-of-pocket payments increased substantially, in particular in the poorer ex-Soviet countries, undermining the equity, efficiency and transparency of health care systems. ${ }^{20}$

Thus, while some countries in Europe had to reduce publicly financed coverage, others, including Belgium, France, Ireland, and the Netherlands, moved in the opposite direction and expanded entitlement to publicly funded health care. ${ }^{19}$ Ireland introduced universal entitlement to both hospital (1991) and primary care (2006), the latter subject to capped costsharing for higher income households. ${ }^{24}$ In 2000, France introduced universal coverage, changing the basis of entitlement to publicly funded care from employment to citizenship and entitling those with low incomes to free coverage. ${ }^{25}$ Belgium, in 2008, extended full statutory coverage to all self-employed people, creating a single health risk pool for the first time. ${ }^{26}$ Finally, in 2006 the Netherlands abolished the traditional divide between a compulsory social health insurance scheme for all employees with an income below a certain threshold and private health insurance for the remaining 30 percent of the population, so that the whole population became covered by a single health insurance scheme, operated by competitive private insurance funds. ${ }^{27}$ These changes to coverage resulted in greater financial equity and protection, as well as more equitable access to care. ${ }^{19}$ 
A number of European countries have undertaken attempts to depoliticize decisions on rationing by using tools such as HTAs and setting up dedicated HTA agencies. In Sweden, economic assessments are combined with humanitarian and solidarity principles, as well as public involvement. ${ }^{28}$ Another example that has received international attention is the National Institute for Health and Clinical Excellence (NICE), set up in the United Kingdom in 1999 to reduce variations in the availability and quality of National Health Service (NHS) treatments and care in different parts of the country (the so-called 'postcode lottery'). When appraising new technologies and issuing guidance, NICE reviews clinical and economic evidence, relying particularly on quality-adjusted life years (QALYs), and usually setting an upper threshold of GBP $£ 30,000$ per QALY. Several high profile cases, however, demonstrated that the government, the pharmaceutical industry and the media continue to wield influence on NICE recommendations, raising the question of which social values to uphold and how to make decisions on them..$^{11,28,29}$

\section{DISCUSSION}

Resource allocation and rationing raise many ethical questions that differ considerably between the US and Europe. In the US, the breadth of coverage is a major issue, with a large part of the population left uninsured or poorly insured. In contrast, in most of Europe, population coverage is nearly universal. The major reason behind this difference is that Europefollowing the devastation of the Second World War-embraced various models of the welfare state built on the underlying notion of solidarity, whereas the US never faced that level of devastation and remained much more heterogeneous in its political values.

These underlying perceptions of the welfare state have a direct impact on other aspects of rationing. The US, where social welfare remains politically controversial, places few restrictions on publicly financed health care technology, such as in the Medicare and Medicaid programs, regardless of cost or clinical effectiveness. ${ }^{13}$ European countries, on the other hand, are more willing to engage in explicit debates about what the limits of publicly funded health care should be. However, they face difficulties in putting these debates on a rational basis and limiting media and lobby power, with implications for the values that underpin decisions. 


\section{CONCLUSION}

Given the very different contexts of health care systems in the US and Europe, it is not surprising that ethical issues around rationing differ substantially. In the US, they largely revolve around rationing care by eligibility for insurance coverage, whereas in Europe they are more concerned with the scope of publicly funded services to all. With PPACA, the US has taken a major step towards expanding population coverage, effectively, but slowly, following the example of European countries. Faced with a sustained economic crisis, there is a growing recognition on both sides of the Atlantic of fiscal constraints and the need to contain health care costs. However, PPACA does little to address rising health care expenditure, ${ }^{30}$ as an explicit discussion of rationing remains politically anathema in the US. ${ }^{13}$ What seems to be urgently needed in both the US and Europe are public debates about the financial sustainability of health systems, the trade-offs between cost-containment and broader societal and health system goals (such as increased population coverage and investment in other social goods), the role of the welfare state, and where the limits of publicly financed health care should be.

\section{Acronyms List:}

HTA $=$ Health technology assessment

NICE = National Institute for Health and Clinical Excellence

PCORI = Patient-Centered Outcomes Research Institute

PPACA = Patient Protection and Affordable Care Act

QALY = Quality-adjusted life year

Conflicts of Interest: None declared.

\section{REFERENCES}

1. Ubel P, Goold S. 'Rationing' health care. Not all definitions are created equal. Arch Intern Med. 1998;158:209-14.

2. Beauchamp T, Childress J. Principles of Biomedical Ethics, Sixth Edition. Oxford, New York: Oxford University Press; 2008.

3. World Health Organization. World Health Report 2000. Health systems: improving performance. Geneva: WHO; 2004.

4. Duran A, Kutzin J, Martin-Moreno J, Travis P. Understanding health systems: scope, functions and objectives. In: Figueras J, McKee M, editors. Health Systems, Health, Wealth and Societal Well-being Assessing the Case for Investing in Health Systems. Maidenhead: Open University Press; 2012. p. 19-36. 
5. Rechel B, Thomson S, van Ginneken E. Health systems in transition: template for authors. Copenhagen: World Health Organization, on behalf of the European Observatory on Health Systems and Policies; 2010.

6. Askildsen J, Holmas T, Kaarboe O. Monitoring prioritisation in the public health-care sector by use of medical guidelines. The case of Norway. Health Econ. 2011;20:958-70.

7. Fendrick AM, Cherew M. Value-based insurance design: aligning incentives to bridge the divide between quality improvement and cost containment. Am J Manag Care. 2006;12:SP5-10.

8. Thomson S, Foubister T, Figueras J, Kutzin J, Permanand G, Bryndová L. Addressing financial sustainability in health systems. Copenhagen: World Health Organization, on behalf of the European Observatory on Health Systems and Policies; 2009.

9. McKee M, Figueras J. Strategies for health services. In: Detels R, McEwen J, Beaglehole R, Tanaka H, editors. Oxford Textbook of Public Health, Fourth Edition. Oxford: Oxford University Press; 2002. p. 1889-909.

10. Saltman R, Figueras J, editors. European health care reform. Copenhagen: World Health Organization Regional Office for Europe; 1997.

11. Klein R. Rationing in the fiscal ice age. Health Econ Policy Law. 2010;5:38996.

12. Russell J, Greenhalgh T, Burnett A, Montgomery J. "No decisions about us without us"? Individual healthcare rationing in a fiscal ice age. BMJ. 2011;342:d3279.

13. Gusmano M, Allin S. Health care for older persons in England and the United States: a contrast of systems and values. J Health Polit Policy Law. 2011; 36(1):89-118.

14. Centers for Medicare \& Medicaid Services. National health expenditure data. Available from URL: https://www.cms.gov/NationalHealthExpendData/25_ NHE_Fact_Sheet.asp\#TopOfPage (accessed 5 January, 2012). Baltimore: CMS; 2012.

15. Organization for Economic Co-operation and Development. Health at a glance 2011. Available from URL: http://www.oecd.org/document/11/0,3746,en_ 2649_37407_16502667_1_1_1_37407,00.html (accessed 5 January, 2012). Paris: OECD; 2011.

16. Fielding J, Teutsch S, Breslow L. A framework for public health in the United States. Public Health Reviews. 2010;32:174-89.

17. Elmendorff D. CBO's analysis of the major health care legislation enacted in March 2010. Testimony before the Subcommittee on Health Committee on Energy and Commerce, U.S. House of Representatives. March 30, 2011. Available from URL: http://www.cbo.gov/publication/22077 (accessed 21 June, 2012). Washington DC: Congressional Budget Office; 2011.

18. Institute of Medicine. The Healthcare Imperative: Lowering Costs and Improving Outcomes. Washington, DC: The National Academies Press; 2009. 
19. Thomson S, Foubister T, Mossialos E. Financing health care in the European Union: challenges and policy responses. Copenhagen: World Health Organization, on behalf of the European Observatory on Health Systems and Policies; 2009.

20. Rechel B, McKee M. Health reform in Central and Eastern Europe and the former Soviet Union. The Lancet. 2009;374:1186-95.

21. European Commission. Eurostat data. Available from URL: http://epp.eurostat. ec.europa.eu/portal/page/portal/statistics/search_database (accessed 26 February, 2012). European Commission; 2012.

22. Gotsadze G, Gaal P. Coverage decisions: benefit entitlements and patient cost sharing. In: Kutzin J, Cashin C, Jakab M, editors. Implementing Health Financing Reform: Lessons from Countries in Transition. Copenhagen: World Health Organization; 2010. p. 187-217.

23. Rechel B, Khodjamurodov G. International involvement and national health governance: the basic benefit package in Tajikistan. Soc Sci Med. 2010; 70:1928-32.

24. McDaid D, Wiley M, Maresso A, Mossialos E. Ireland: health system review. Health Syst Transit. 2009;11:1-268.

25. Chevreul K, Durand-Zaleski I, Bahrami S, Hernández-Quevedo C, Mladovsky P. France: health system review. Health Syst Transit. 2010;12:1-291.

26. Gerkens S, Merkur S. Belgium: health system review. Health Syst Transit. 2010;12:1-266.

27. Schäfer W, Kroneman M, Boerma W, van den Berg M, Westert G, Devillé W, et al. The Netherlands: health system review. Health Syst Transit. 2010;12:1-229.

28. Moreiro T. Health care rationing in an age of uncertainty: a conceptual model. Soc Sci Med. 2011;72:1333-41.

29. Brown P, Calnan M. Political accountability of explicit rationing: legitimacy problems faced by NICE. J Health Serv Res Policy. 2010;15:65-6.

30. Wilensky G. Re-engineering health systems: The U.S. experience. Soc Sci Med. 2011;74:674-6. 